Texto
Informativo

Eliana do Pilar Rocha Roberto de Souza Martins

(UFPR)

\section{Terra e Território Faxinalense no Paraná: notas sobre a busca de reconhecimento}

Em virtude dos conflitos resultantes de reduções territoriais, degradações ambientais e perda de patrimônio imaterial, além de sistemáticas violações dos direitos humanos proporcionadas pela invisibilidade social a que se acham sujeitos, representantes de diversas comunidades faxinalenses do Paraná apresentaram no dia 3 de julho de 2007, no Plenário da Assembléia Legislativa do Estado do Paraná, um dossiê de denúncias que fazem referência às sistemáticas e permanentes arbitrariedades contra a integridade física, ambiental e sócio-cultural destas comunidades.

Faxinais são comunidades rurais que se estabeleceram no centro-sul do Paraná e que se constituíram historicamente como mecanismo de autodefesa do campesinato local buscando assegurar sua reprodução social em conjunturas de crise econômica como a do tropeirismo e durante o ciclo da erva-mate, ou seja, entre meados do século XIX e a década de 30 do século $X X$.

Tais comunidades possuem formas peculiares de apropriação do território tradicional, baseadas no uso comunal das áreas de criadouros de animais, recursos florestais e hídricos e no uso privado das áreas de lavoura, onde é praticada a policultura alimentar de subsistência com venda de pequeno excedente. Baseados em normas de conduta e de uso ambiental próprias, sobretudo na combinação de uso comum e privado dos recursos naturais, os faxinais são considerados uma forma de organização camponesa diferenciada no sul do país.

Contando com a presença de representantes políticos do Estado do Paraná, além de integrantes da Comissão Pastoral da Terra, do Instituto Nacional de Colonização e Reforma Agrária, do Instituto de Terras, Cartografia e Geodésia e do Instituto Equipe de Educadores Populares, o dossiê exibiu um cenário de instabilidade e deslegitimação de acordos tradicionais que implicam em conflitos de uso dos recursos naturais e da terra.

Tal dossiê lista os principais conflitos com o agronegócio, tanto em faxinais enquadrados como Área Especial de Uso Regulamentado - ARESUR (atualmente dez) como nos ainda não reconhecidos por este instrumento jurídico estatal, porém 
protegidos pelos dispositivos constitucionais. A ARESUR é o mecanismo de reconhecimento formal do território faxinalense através de legislação estadual, conforme o Decreto 3.446/97. Sob este enquadramento os faxinais são reconhecidos como "sistemas de produção camponesa que têm como traço marcante o uso coletivo da terra para produção animal e conservação ambiental" (IPARDES, Anuário Físico-Ambiental 2004).

Outro mecanismo de reconhecimento está nas Leis Municipais, como as de $n^{\circ} 09$ de 06/02/48 e $n^{\circ} 149$ de 06/05/77, de São João do Triunfo e Palmeira, respectivamente, as quais buscam delimitar responsabilidades inerentes ao uso das terras de agricultura e de pastagens com as modalidades correspondentes de cercamento.

Os conflitos acerca do acesso e uso dos recursos hídricos e agroflorestais também são itens constantes do dossiê, como o desmatamento de nascentes, contaminação e colocação de fechos, caracterizados pela colocação de cercas no interior dos criadouros por novos proprietários de terras, denominados "neo-rurais" pelos faxinalenses, ou seja, novos moradores que, desconhecedores das práticas comunitárias, cercam porções do território com a finalidade de isolar a área para uso privado, ato notadamente acompanhado por desmate e posterior plantio de pinus ou erva-mate, ou ainda plantação de milho e soja. Desse modo, o dossiê denuncia a fragilidade dos recursos naturais - água, pastagens, ervas, produtos madeiráveis e terra - frente à contaminação de fontes de água, derivação de venenos e plantio de florestas homogêneas de pinus sobre nascentes.

O dossiê manifesta principalmente, no entanto, a violência física contra as lideranças faxinalenses e seus bens como lesão corporal, tentativa de homicídio, incêndios criminosos, danos à criação, roubo de criação, pistolagem e homicídios, além de envenenamento de fontes, fechos e outros.

Uma vez que tal documento reúne denúncias registradas em apenas dez dos 45 faxinais identificados no Estado pela Comissão Pastoral da Terra e organizações não-governamentais, o próprio dossiê reconhece que o que se expõe é apenas uma pequena parcela das formas de conflitos existentes na realidade faxinalense.

De qualquer modo o documento teve como objetivo principal denunciar aos órgãos públicos, sobretudo às autoridades ambientais como o Instituto Ambiental do Paraná (IAP), a Secretaria do Meio Ambiente (SEMA), o Ministério do Meio Ambiente (MMA), o Instituto Brasileiro de Meio Ambiente e dos Recursos Naturais Renováveis (IBAMA) e prefeituras municipais, os conflitos entre as comunidades autodefinidas como faxinalenses e o denominado agronegócio.

Sua principal meta era a de acionar o direito étnico e coletivo contra os processos de desterritorialização e as formas de violência a que estão sujeitos os faxinalenses, bem como fornecer visibilidade social e política a essas comunidades tradicionais, ampliando os lugares políticos de participação, buscando novas relações com o Estado e reafirmando a noção de direito dos faxinalenses com relação ao uso comum da terra e como gestores de recursos naturais a partir de práticas comunitárias que permitem a associação do conhecimento tradicional à conservação do ecossistema.

O criadouro comunitário, área cercada que caracteriza o sistema de uso comum de pastagens, se forma e se conserva mediante a produção consensuada de práticas sociais internas e laços de solidariedade. É nesse espaço que se encontram as moradias, normalmente cercadas em pequenas áreas de terra denominadas de quintais, lugar de produção de hortaliças e pequenas culturas de subsistência. Ao redor da área de uso 
comum, ou mesmo distante, encontra-se o complemento do faxinal, isto é, as áreas de lavoura compostas, geralmente, de pequenas parcelas de terra de uso agrícola privado onde prevalecem as culturas do milho, fumo, feijão e arroz.

No entanto, os mecanismos de mercado e seus ciclos expansionistas, que atuam tanto pelo avanço do agronegócio das monoculturas de soja e milho como pelo reflorestamento de pinus, a partir das décadas de $60 \mathrm{e}$ 70 do século $X X$, substituem estas áreas de lavoura por grandes fazendas de soja e milho ou áreas de plantação de pinus.

Neste cenário gerou-se uma crise no confronto das formas de apropriação dos recursos ambientais representadas, por um lado, pelo modelo tradicional faxinalense e, do outro, pelo modelo de agricultura convencional, legitimada e reconhecida com o status das políticas governamentais, que culmina na transformação das áreas de uso comum em áreas de uso individual e com o vínculo do faxinalense a contratos com empresas fumageiras e com o assalariamento temporário.

Segundo o IAP - Instituto Ambiental do Paraná, dos 152 faxinais que existiam no Estado na década de 90, existem hoje apenas 44 comunidades no centro-sul paranaense que mantêm o sistema de criadouro comunitário e o uso coletivo de terras, somando uma área total de aproximadamente 26.189 hectares e cerca de 3.409 famílias, com uma área média por criador comunitário/família de 1,8 hectare.

No intuito de promover ações reivindicativas que fizessem frente aos antagonistas e a interesses do Estado, representantes de 34 faxinais, com base em fatores de auto-reconhecimento, sobretudo o de territorialidade específica, reuniram-se no $1^{\circ}$ Encontro dos Povos dos Faxinais, em 2005, no qual organizaram a "Articulação Puxirão", movimento social que busca a representação política junto ao Estado e propôs como pauta de negociação três itens principais, quais sejam: a questão fundiária, a construção de planos de uso sustentável do território e o resgate das práticas e conhecimentos tradicionais.

Realizado no município de Irati nos dias 5 e 6 de agosto de 2005 e tendo como lema "Terras de Faxinal: Resistir em puxirão pelo direito de repartir o chão", esse primeiro encontro reuniu faxinalenses que, buscando a construção da identidade de comunidade tradicional de forma coletiva, elaboraram propostas para conservação de seus territórios tradicionais, apoiados pela Comissão Pastoral da Terra, Movimento dos Pequenos Agricultores, Associação de Grupos de Agricultores Ecológicos São Francisco de Assis, Associação dos Grupos de Agricultores Ecológicos do Turvo, Instituto Ambiental do Paraná, Rede Faxinal e Instituto Equipe de Educadores Populares.

Contando com representantes dos faxinais dos municípios paranaenses de Irati, Mallet, Prudentópolis, Quitandinha, Rebouças, Rio Azul, São João do Triunfo, São Mateus do Sul, Turvo, Antônio Olinto, Boaventura de São Roque, Mandirituba, Ponta Grossa e Pinhão, foram promovidas oficinas para discussão de diversos assuntos como o agronegócio e seu impacto negativo, a criação de organizações locais em cada faxinal, como associações, grupos ou cooperativas, direito, legislação, agroecologia e agrofloresta, além de assuntos relacionados à cultura, religiosidade, saúde popular e ofícios tradicionais.

Observando-se como "povos tradicionais" numa diversidade de formas de reconhecimento jurídico dentro de diferentes modalidades de apropriação dos recursos naturais que caracterizam as "terras tradicionais", sobretudo nas modalidades de cercamento, os faxinalenses reconheceram-se como categoria nos termos do 
Decreto 6.040/2007. A partir daí a "Articulação Puxirão" buscou participação em diversos cenários como a Comissão Nacional de Desenvolvimento Sustentável das Comunidades Tradicionais e a Comissão de Estudos Fundiários sobre Comunidades Tradicionais, assim como por meio do Projeto de Levantamento Sócio-Econômico em comunidades faxinalenses, coordenado pelo Instituto Equipe de Educadores Populares em parceria com outras organizações não-governamentais.

A "Articulação Puxirão" se apresenta como um instrumento de denúncia e conhecimento público dos conflitos agrários e socioambientais em áreas de faxinais, além de trazer à luz a existência coletiva dos faxinalenses e seus mecanismos de reivindicação do território tradicional através de mobilizações, abaixo-assinados, registros de acordos de uso comum e assembléias comunitárias para deliberação de suas ações.

$\mathrm{O}$ posicionamento dos faxinalenses em defesa de seus interesses contra as diversas arbitrariedades promovidas pelo agronegócio e seu aspecto violento e coercitivo mostra não só a condição de grupo mobilizado e articulado na forma de movimento social, bem como a tentativa de enfrentamento pelas lideranças faxinalenses motivadas pela expectativa de direitos étnicos garantidos pelos Artigos 215 e 216 da Constituição Federal e 68 das Disposições Constitucionais Transitórias, pela Convenção 169 da Organização Internacional do Trabalho e pelo Decreto 6.040/07, além de outros dispositivos infraconstitucionais.

\section{Contatos}

Articulação dos Povos Faxinalenses

faxinalenses@bol.com.br

(42) 8407-8233

Instituto Equipe de Educadores Populares

institutoequipe@brturbo.com.br

(42) 3422-5619

CPT - Equipe Guarapuava

guarapuava@cpt.org.br

(42) 3622-5599 